\title{
Paragens e passagens: a autobiografia para além da primeira pessoa em E agora? Lembra-me
}

\author{
Mariana Duccini Junqueira da Silva*
}

\begin{abstract}
Resumo: O documentário português E agora? Lembra-me (2013) registra, à maneira de um diário íntimo, o período em que o realizador Joaquim Pinto se submete a um tratamento contra o HIV, do qual é portador há duas décadas. A conversão dessa experiência em filme dá compleição a memórias que perecem diante da iminência da morte. Enunciada em primeira pessoa, a obra ultrapassa as eventuais limitações do dispositivo que a engendra para se lançar a uma reflexão sobre o tempo e a impermanência.
\end{abstract}

Palavras-chave: documentário português contemporâneo; E agora? Lembra-me; primeira pessoa; diário; memória.

Resumen: El documental portugués E agora? Lembra-me (2013) registra, en forma de diario íntimo, el período en el que el director Joaquim Pinto se somete a un tratamiento contra el VIH, del que es portador hace dos décadas. La conversión de esta experiencia en película da complexión a memorias que perecen ante la inminencia de la muerte. Enunciada en primera persona, la obra va más allá de las posibles limitaciones del dispositivo que la engendra para lanzarse en una reflexión sobre el tiempo y la impermanencia.

Palabras clave: documental portugués contemporáneo; E agora? Lembra-me; primera persona; diario; memoria.

Abstract: Portuguese documentary E agora? Lembra-me (2013) is a vídeo-diary by and about the director Joaquim Pinto in his year of clinical studies with yet unnaproved drugs against HIV (the director has been living with the vírus for almost twenty years). The experience, converted to film, strengthens memories which perish at the threat of death. The first-person enunciation overcomes the dispositive's contingent limitations and the narrative launches itself into a reflexion about time and impermanence.

Keywords: contemporary portuguese documentary; E agora? Lembra-me; first-person; diary; memory.

Résumé: Le documentaire portugais E agora ? Lembra-me Me (2013) enregistre, à la manière d'un journal intime, la période pendant laquelle le directeur Joaquim Pinto a subit un traitement contre le VIH, dont il est porteur depuis deux décennies. La conversion de cette expérience en film donne aux souvenirs, devant l'imminence de la mort, une teinture évanescente. Enoncé à la première personne, le travail va audelà des limites du dispositif qui l'engendre pour lancer une réflexion sur le temps et l'impermanence.

Mots-clés: documentaire contemporain portugais; E agora? Lembra-me; première personne; daily; memory.

\footnotetext{
* Instituto de Ensino e Pesquisa - Insper, Graduações em Economia e Administração de Empresas. 04546-042, São Paulo, Brasil. E-mail: marianaduccini@gmail.com
}

Submissão do artigo: 08 de dezembro de 2015. Notificação de aceitação: 13 de fevereiro de 2016. 
"Há dois anos, comecei a anotar num mapa os dias bons e os dias maus. Desisti ao fim de um mês. Eram quase todos maus". No curso de 2011, os dias maus que soterravam os bons conformavam o cotidiano do realizador português Joaquim Pinto, que há aproximadamente duas décadas convive com o vírus do HIV em co-infecção com a hepatite C. Registrar, à maneira de um diário, o percurso de um tratamento com drogas experimentais realizado na Espanha, a desagregação do corpo físico e certa confusão mental causadas pelos efeitos colaterais dos medicamentos representava não apenas uma forma de permanecer vivo, mas sobretudo de conferir compleição a memórias e percepções que pereciam diante da iminência da morte.

Convertidas em filme, as notas diárias de Pinto exorbitam a dimensão do registro autobiográfico e do diarismo. Entrelaçam temporalidades, imbricando os tempos da doença, da juventude do realizador, dos amigos mortos, dos eventos históricos pretéritos e atuais, da própria cosmologia. Revela a condição de uma identidade enunciativa que, algo descentrada, só se perfaz de modo relacional.

E agora? Lembra-me (2013) é o trabalho do "lembrar-se do agora", em que a situação de um sujeito em risco de desaparecimento legitima o olhar reflexivo quanto ao momento de seus contemporâneos. Eivado tanto de multiplicidades quanto de dissensões, esse exercício de rememoração compõe-se com imagens e sons que restarão à implacabilidade da morte, mas nem por isso reconhece na aventura da vida uma experiência humano-centrada.

A transitoriedade e a recência do homem (e, mais especificamente, do sujeito enunciador) em relação a outras formas biológicas desmobilizam o "antropocentrismo renitente" (Comolli, 2008) que supõe um olhar que se dirige do homem ao mundo, mas não o inverso. As memórias autobiográficas ultrapassam, assim, a mera inscrição em primeira pessoa em um documentárioprocesso que, pelos recursos estéticos da duração (como olhar que se detém), do comentário em voz over (cuja inflexão tanto respalda um lugar de autoria quanto remete aos limites, nunca obliterados, desse posicionamento) e da heterogeneidade de registros audiovisuais, tematiza as existências em curso: não "a vida", mas o "em vida".

É assim que E agora? Lembra-me, ao mesmo tempo em que contempla a Aids em sua semantização histórico-cultural (com a asserção de que "cada século tem sua doença"), enfatiza a dimensão radicalmente biológica do HIV e de outros micro-organismos em seus modos de interação com a vida. São essas formas microscópicas que historicamente vêm levando a melhor, reinventando-se para permanecer. $O$ gesto do filme, nesse sentido, desmonta a ilusão de preponderância da espécie humana (tanto mais nuançada e posta em 
questão quando das imagens que expõem a agressão à natureza, o colapso das economias europeias, a falência do sistema público de saúde, o apelo a drogas sintetizadas que substituem os ancestrais alteradores de consciência). Mas não se trata, tampouco, de uma descrença derrisória na potencialidade humana.

O filme é eivado de intensidade ao aludir ao amor entre o realizador e Nuno Leonel, seu companheiro, com quem compartilha a vida e o trabalho; ao trato com os quatro cachorros criados pelo casal; ao reencontro com amigos de longa data e à celebração daqueles que já não existem (caso, entre outros tantos, do também realizador João César Monteiro); à amizade com vizinhos como Deolinda, velha aldeã que conhece os segredos das plantas. Todo um mundo que logo estará convertido em matéria de memória, aspecto em que o cinema de Joaquim Pinto se entrelaça com a vida: não a monumentaliza, mas a envolve com algum desejo de permanência. Registros da ausência iminente que se presentifica em filme.

O trabalho memorialístico alcança em E agora? Lembra-me uma dimensão coletiva. Inscrito em primeira pessoa, desliza, entretanto, das eventuais limitações do dispositivo que engendra o documentário (o diário íntimo ou o caderno de notas) para se lançar a uma reflexão sobre o tempo e a impermanência. Afirma singelamente a vida, imiscuindo-se em seus ritmos na duração e na composição de cada um dos planos.

\section{A experiência subjetiva para além do eu autorreferencial}

Uma espécie de "inflação" da primeira pessoa em diferentes produções da contemporaneidade perpassa não apenas as autobiografias, as literaturas confessionais, o cinema, os trabalhos performáticos no campo das artes e a fotografia, mas também certos programas jornalísticos, os reality shows e a própria dinâmica das redes sociais. É nessa medida que a presença de um eu que enuncia, performa, testemunha, experimenta em sentido patético os efeitos da experiência a que está exposto (voluntariamente ou não), rentabiliza um efeito de autenticidade a essas produções. Tais investidas tendem a um processo de espetacularização orientado a converter as vivências particulares em realidades ficcionalizadas por meio de recursos midiáticos (Sibilia, 2013). Não raro, os sentidos propostos por essas narrativas esgotam-se no intimismo autorreferencial e exibicionista, em uma ordem em que o "fazer-se visível" torna-se a medida da existência.

Tal "despotencialização" da subjetividade e do corpo próprio, cuja conversão em imagem obedece a uma roteirização conforme às implicações da sociedade de consumo, lastreia a produção de imaginários que estabelecem 
uma "gramática de aparências" (Safatle, s.d: s.p.), modulando padrões de socialização e de identificação entre os sujeitos.

Em E agora? Lembra-me, as formas de instalação da primeira pessoa subvertem esse panorama - e chegam a relativizar a autoridade enunciativa que emanaria de um eu autocentrado. A patente dissolução do corpo físico do realizador, assim como a eventual confusão das ideias que ele expressa, decorrentes do tratamento médico, desmobilizam o culto a um corpo intocado e incorruptível. É, ao contrário, em termos de uma existência fragilizada, em declínio, que o lugar enunciativo da primeira pessoa se torna potente na tessitura fílmica. Assume uma vocação política na contracorrente das narrativas que espetacularizam a intimidade, dimensionando a experiência individual no âmbito da finitude e, mais além, relativizando a preponderância do homem na ordem da natureza: "A minha vida não tem nada de particular. Um grão de tempo e eu virarei pó", expressa um dos comentários em voz over que sintetizam esse posicionamento.

A imagem de um corpo assim destinado ao pó, reduzido à sua espessura puramente orgânica, demarca-se como emblema identitário em uma das primeiras sequências: o realizador alude a um problema na própria dicção ao explicar que os remédios deram-lhe cabo de alguns dos dentes, mas reconhece (não sem ironia) a necessidade de manter o otimismo. "Começo com um sorriso", diz, enquanto a câmera se detém na imagem de um raio-X de seu crânio, com a arcada dentária abrindo-se no funesto esgar da caveira, alegoria da irremediável sujeição de toda existência à morte:

A história em tudo o que nela desde o início é prematuro, sofrido e malogrado se exprime num rosto - não, numa caveira. E porque não existe, nela, nenhuma liberdade simbólica de expressão, nenhuma harmonia clássica da forma, em suma, nada de humano, essa figura, de todas a mais sujeita à natureza, exprime não somente a existência humana em geral, mas, de modo altamente expressivo, e sob a forma de um enigma, a história biográfica de um indivíduo. (Benjamin, 1984: 188).

O tema do fatalismo a que se destina qualquer empreitada autobiográfica é propulsionado no filme, paradoxalmente, como um exercício de crença: "Tenho de querer para crer". O sentido da própria finitude (e do irresistível movimento que germina a destruição em todas as formas de vida) impregna a composição imagética do filme, sobretudo em relação aos fragmentos que suscitam um trabalho crítico da memória. É nesse âmbito que boa parte das imagens agenciadas traz em si o caráter da falta: o passado que se faz presente na imagem enquanto signo da própria ausência (Ricoeur, 2006). A imagem crítica, assim, é aquela que traz à percepção o sentido de uma distância irreparável: o lapso ou o instante fugidio que faz confrontar, no interior dessa imagem, tudo 
o que resta em face de tudo o que fora perdido, a relação entre um elemento do passado e um "ter-lugar" que lhe fora próprio (Didi-Huberman, 2010: 174), ora visível apenas como signo da ausência.

Esse exercício dimensiona a escritura fílmica em sua vocação arqueológica, contrapondo à iminência da morte as imagens que a ela sobreviverão, fragmentos não apenas da narrativa de uma existência em particular, mas também da vida em suas múltiplas formas. O tema da sobrevivência - e das temporalidades forçosamente relativas dos seres que compartilham a longa história do mundo - responde a um trabalho estético com a duração, que se mobiliza ora em termos da extensividade dos eventos (em especial os que representam os ciclos da natureza) ora em termos da condensação deles (caso das figurativizações em que a presença e a atuação do homem são enfatizadas).

A exemplo da duração extensiva, no longo plano-sequência inicial, a câmera se detém no deslocamento de uma lesma, acompanhando seu vagar até que o animal saia completamente do quadro. Pela natureza da composição, a imagem suscita junto ao espectador uma percepção que Deleuze e Guattari (1997) caracterizam como háptica (mais tátil do que propriamente visual), propondo uma espécie de contato próxima ao toque, de forma a "encurtar" a distância típica da contemplação voyeurística. No âmbito da condensação, a montagem em inserts relaciona eventos históricos em uma sequência que figurativiza desde o 25 de abril de 1974 - quando o sentido de liberdade floresce e filmes até então banidos pela censura tomam os cinemas em Portugal - até a morte em decorrência da Aids, ao longo das décadas seguintes, de figuras célebres da intelectualidade e das artes, como Michel Foucault, Guy Hocquenghem, Rock Hudson e Serge Daney. Ora o efeito proposto não é mais o de imersão (como na sequência da lesma) ${ }^{1}$, mas o de distanciamento - e de uma certa vertigem, em vista da rápida sucessão dos planos e da agilidade da voz over, que enumera os acontecimentos.

Uma profusão de memórias que se esfumaçam no curto intervalo da vida humana parece restringir o tempo dos homens à dimensão do chronos, quando o comentário em voz over, criticamente, aponta para uma nostalgia em relação

1. A propósito da motivação para esta sequência, Joaquim Pinto, em entrevista ao jornal Expresso, alude a uma fábula que, mesmo não aparecendo literalmente no filme, respalda a presença da figura da lesma na narrativa de E agora? Lembra-me: "Um homem, o primeiro da Terra, encontra uma lesma e começa a conversar com ela. A lesma diz-lhe que não há tempo. O homem desata então a correr, sem parar. Até hoje. Talvez a lesma lhe estivesse a dizer que o 'tempo instantâneo', independente de outras realidades, não existe" (Ferreira, 2014). Reproduzimos aqui o comentário do realizador por entendermos que ele sintetiza, poeticamente, a relação entre extensividade e condensação no trabalho com a duração dos planos, que propomos nesta análise. 
ao kairos: "Não me lembro do que fiz ontem, mas sinto um cheiro de infância. É triste andar por entre Deus ausente". ${ }^{2}$

As tematizações sobre o cotidiano particular do realizador são contempladas numa perspectiva que, embora assuma a cronologia, situa-se além dela. Nas vicissitudes que frequentemente o impeliram a "começar do zero, com o Nuno", Joaquim Pinto rememora os trabalhos no cinema (como engenheiro de som, produtor e realizador), as constantes viagens, os amigos que vão morrendo, os sete anos vividos na Ilha dos Açores, o crescimento dos cães de estimação, o primeiro ensaio clínico com as drogas experimentais e o retorno ao continente. Nesse feixe de memórias, a rodagem de $O$ novo testamento de Jesus Cristo segundo João, ${ }^{3}$ obra que o realizador caracteriza como um convite ao amor absoluto, expressa também a limitação da linguagem diante de toda experiência que se vive - ideia que parece explicar a opção estética pela reunião de fragmentos imagéticos francamente heterogêneos em $E$ agora? Lembra-me.

A acumulação de imagens e sons, ao mesmo passo em que aponta para uma tentativa de se conferir alguma lógica e algum sentido à aventura da vida, também expressa quão infausta tende a ser essa empreitada. O filme, nesse âmbito, tem na prática das citações (verbais e imagéticas) uma de suas estratégias de composição, recorrendo a diferentes posições enunciativas para perfazer um lugar de autoria: "Assim se desvenda o ser total da escritura: um texto é feito de escrituras múltiplas, oriundas de várias culturas e que entram umas com as outras em diálogo, em paródia, em contestação" (Barthes, 2004: 64).

Essa multiplicidade de escrituras, ao agenciar também os "textos da natureza" (as frequentes composições que acolhem o tempo próprio das plantas, vírus e seres não racionais), não faz com que o documentário prescinda, entretanto, de uma vocação política. Se as guerras ao redor do mundo, expostas na maioria das vezes em segundo plano (em imagens que provêm de televisões ou de computadores portáteis), parecem em certa medida distantes, torna-se bem próxima a realidade decadente do sistema público de saúde, que quase acarreta a interrupção forçada do tratamento de Joaquim Pinto na Espanha.

A constatação de que "As drogas da crise são outras", materializada enquanto a câmera passeia pelas ruas de Casal Ventoso (bairro de Lisboa outrora célebre pelo comércio de entorpecentes), referencializa a alienação do homem contemporâneo quanto a substâncias que facultariam o autoconhecimento, o que nos legou, por um lado, a banalização dos antidepressivos e, por outro, "a estúpida política repressiva". Mas a crítica também se volta contra uma ade-

\footnotetext{
2. O verso "É muito triste andar por entre Deus ausente" encontra-se no poema "A mão no arado", de Ruy Belo.

3. Documentário dirigido por Joaquim Pinto e Nuno Leonel (2013).
} 
são irrefletida aos discursos científicos que tornariam palatável uma espécie de novo darwinismo social, ao relacionar a vocação humana de enganar e abusar a um determinismo genético, exemplo da retórica em que o ideal humanista há muito perdera força: "Vivemos tempos fluidos, mas as verdades continuam a vender bem".

Dentre essas verdades prontas ao consumo, adensa-se o impasse entre morrer da doença ou morrer da cura, em face de um corpo violentado pelas drogas experimentais que compõem o tratamento. As insônias e os pesadelos, assim como o raciocínio intermitente e a falta de disposição física do realizador, revelam uma extenuante, mas não amargurada, negociação com a morte, em que o ato cinematográfico se perfaz com as matérias de um mundo sobrevivente, "revanche derrisória da arte sobre as epidemias" (Gester, 2014). À luz dessa revanche da arte, o lugar da primeira pessoa no documentário de Joaquim Pinto funciona como um liame entre as diversas memórias imagéticas e sonoras que exorbitarão a finitude empírica do autor, forma paradoxal de afirmação de um $e u$ que ultrapassa a própria contingência.

\section{As imagens de um mundo em profanação}

Um dos motivos recorrentes na estruturação de E agora? Lembra-me, no que diz respeito ao já referido exercício com as citações verbais e imagéticas, é a presença da obra De Aetatibus Mundi Imagines [As Imagens das Idades do Mundo], de Francisco de Holanda, considerado um dos principais expoentes do Renascimento português. O original da obra, uma crônica do mundo em imagens (composta entre 1543 e 1573), é mantido na Biblioteca Nacional de Espanha, e as pinturas presentes no livro são perscrutadas por Joaquim Pinto, que revela certa obsessão com a ideia de "Como se imaginava o tempo antes de haver tempo e antes de haver homens". ${ }^{4}$ Detido em uma representação de Afrodite e Eros, o realizador, em um lapso, pensa ter lido no desenho a palavra "Nuno" (o nome de seu companheiro). Tratava-se, entretanto, do primeiro vocábulo de uma célebre citação de Virgilio: "Nunc scio quid sit amor" ["Agora sei o que é o amor"].

O reconhecimento, ainda que por equívoco, do nome da criatura amada em uma imagem que tematiza precisamente o amor dimensiona a presença de Nuno Leonel no documentário. Inicialmente refratário a participar da rodagem, Nuno aos poucos adere ao projeto, que acaba por se conformar de fato

4. A ausência de figuras antropológicas refere-se especificamente, em De Aetatibus Mundi Imagines, à série de desenhos sobre a Criação do Mundo, em que a Santíssima Trindade é representada por meio de figuras geométricas, tipo de representação muito rara na pintura da época (Deswarte, 1983). 
como uma realização do casal. As situações cotidianas compartilhadas adensam o caráter de filme-processo em E agora? Lembra-me, já que o exercício reflexivo sobrevém como resultado do percurso que a própria obra vai desenvolvendo, sem uma roteirização inflexível, durante o período de "paragem forçada", como Joaquim Pinto se refere ao ano de 2011.

Afrodite e Eros aparece originalmente em De Aetatibus Mundi Imagines fazendo um díptico com a composição Anjo do Senhor. Ironicamente, o pareamento das gravuras na obra de Francisco de Holanda, segundo Sylvie Deswarte, tem por princípio uma desqualificação do amor profano ante o amor sacro:

Face ao Anjo do Senhor, resplandecente de luz, raios e chamas sobre um azul límpido, são figurados Afrodite e Eros como cadáveres esqueléticos, os sexos vazios e secos, em uma ambiência sepulcral e noturna de penhascos recobertos de inscrições. Esse díptico mostra-se da mesma forma, para além do contexto da Crônica do Mundo, como a exaltação do amor sagrado em relação ao amor profano, opondo à eterna beleza divina a perecível beleza terrena, e afirmando, no mesmo golpe, o caráter mortal dos deuses da Antiguidade. (Deswarte, 1983: 111). ${ }^{5}$

A asserção da historiadora da arte torna-se especialmente interessante se a contemplarmos à luz do conceito de Agamben (2007) quanto ao ato de profanação, que encerra o sentido mesmo de restituir os objetos sagrados ao livre uso dos homens, a efetivação da experiência de "um tocar que desencanta e devolve ao uso aquilo que o sagrado havia separado e petrificado" (p. 66).

Nesse âmbito, E agora? Lembra-me é uma elegia à profanação, à consignação das coisas do mundo a seu modo irreparável de existir (Agamben, 2013), sem que a elas seja destinada qualquer forma de suplementação metafísica. Paradoxalmente, essa é também a atividade que pode facultar aos homens um "sair de si" (enquanto locus de uma identidade fixa, unificada): "perderse nas coisas, perder-se até não poder conceber senão coisas. E só então, na experiência da irremediável coisalidade do mundo, chocar-se com um limite, tocá-lo" (p. 96).

O mote do amor profano que converteu em imagem Afrodite e Eros pelos traços e cores de Francisco de Holanda perpassa a história de Joaquim e Nuno, mas "contamina" também o próprio olhar que transforma em matéria audiovisual o mundo sensível no documentário: vidas humanas e não humanas que

5. No original: "Face à l'Ange du Seigneur, resplendissant de lumière, de rayons et de flammes, sur um azur très pur, sont figurés Aphrodite et Eros, à l'état de cadavres squelettiques, aux sexes vides et secs, dans um décor sépulcral et nocturne de rochers recouverts d'inscriptions. Ce diptyque apparait ainsi, sorti du contexte de La Chronique du Monde, comme l'exaltation de l'Amour sacré face à l'Amour profane, en opposant à la beauté divine éternelle la beauté terrestre périssable, et en affirmant du même coup le caractère mortel des dieux antiques". Tradução nossa. 
se mostram em seu modo radicalmente próprio de existência, entregues a um autêntico uso de si. O filme acolhe o "estado das coisas" em uma perspectiva que estende a cada um dos seres seu papel na ordem da vida.

O poder de adaptabilidade e regeneração dos vírus motiva, assim, uma investigação exaustiva do realizador, sobretudo em relação ao HIV, instalado em seu próprio organismo: "Ver para crer, procuro imagens do vírus". $\mathrm{Na}$ aproximação parafrásica à manifestação de São Tomé Apóstolo, que só pôde acreditar no Cristo ressuscitado ao lhe tocar as chagas, desnuda-se a obsessão dos homens pela visibilidade, parâmetro quase indispensável, contemporaneamente, à condição de crença.

Entretanto, as formas naturalmente invisíveis, por ironia, são também as mais antigas e persistentes na aventura da vida. Mas o viés "biologizante" na interpretação sobre esses micro-organismos não subtrai ao filme a análise da dimensão sócio-política das epidemias, com os condicionantes que configuram um tempo e uma história próprios a cada doença. Em paralelo às imagens de laboratório que mostram o HIV, há a conclusão de que, possivelmente, a busca pela verdadeira face do vírus esteja nas imagens da "história não contada no coração das trevas", nos "massacres daqueles que não se submetiam", acompanhada por fotografias que remontam à exploração colonial na África. O tempo e a história da Aids não têm, pois, como se deslindar do tempo e da história da expropriação do homem pelo homem, como também ocorrera outrora com as várias doenças que assombraram a humanidade.

Ainda que originárias de um passado remoto, tornam-se perturbadoras as imagens museológicas que representam a sífilis a partir de moldes de cera (a narração explica que os modelos foram feitos diretamente nos corpos de pacientes infectados, internados compulsoriamente). ${ }^{6}$ Esse choque de percepção não deriva apenas do realismo das peças (certamente indiscutível), mas sobretudo do caráter crítico das imagens, que fazem do jogo da memória uma experiência necessariamente atual: o passado que se torna vertiginoso justamente por precipitar, no presente, as energias aterradoras que identificam a doença em um tempo e um espaço particulares, conformando também as dinâmicas de estigmatização e segregação típicas das moléstias contagiosas (que derivam frequentemente para interpretações moralizantes em relação às epidemias).

Não raro, as doenças mais temíveis são também aquelas a que se atribui uma origem estrangeira, em que o "outro", imaginariamente, é a fonte do mal e da conspurcação:

6. Essas peças compõem o acervo da Colecção de Dermatologia do Hospital Santo António dos Capuchos, em Lisboa. 
A ideia de que as doenças que afligem a Europa vêm de fora faz parte da secular imagem da Europa como entidade cultural privilegiada. Pressupõese a Europa, de direito, isenta de doenças. E os europeus manifestam uma indiferença extraordinária em relação ao impacto devastador que eles próprios - como invasores, como colonizadores - tiveram sobre o mundo exótico e "primitivo". (Sontag, 1989: 59, grifo da autora).

Conforme a câmera revela nos moldes em cera os corpos lacerados pela sífilis, a narração rememora a trajetória da "inofensiva bactéria trazida pelos marinheiros de Colombo" no período ultramarino, que acabou, contudo, por assolar a Europa. Mas critica, ao mesmo turno, a violência colonial e a fobia ao estrangeiro tipicamente europeias, com a ilação de que a sífilis nada teria sido senão a moeda de troca da varíola e do sarampo que as Américas herdaram compulsoriamente dos colonizadores.

Na relação com a alteridade - com os semelhantes, com as diferentes formas de vida que compartilham o espaço do mundo ou até mesmo com aquela que literalmente ameaça a identidade do sujeito (o vírus HIV) -, é tecida a trajetória que o documentário percorre. Pregnante nas várias experiências retratadas, o tema torna-se especialmente lírico quando Joaquim Pinto relembra os primeiros tempos na escola: relata que não se importava com os maus tratos impingidos contra ele pelos professores - implícita relação memorialística com um Portugal sob o jugo da ditadura salazarista -, mas não suportava ver os filhos de pescadores, famintos e descalços, sendo brutalizados. Levava-os então para casa, dava-lhes de comer, deixava que tomassem banho "na banheira grande". As imagens em super-8, mostrando aparentemente crianças genéricas (sem relação referencial com a narrativa) que se abraçam e brincam em uma praia, mais uma vez evocam um amor profano, que dessacraliza as diferenças de nascimento e de posição social - a despeito, sublinha a voz over do realizador, da censura de sua mãe, que ora é percebida como assustadoramente profética: "Esse menino ainda apanha alguma doença".

É nesse espectro que o filme empreende o trabalho de "desmetaforização" tão premente no estudo de Sontag (1989) sobre a Aids. Para a filósofa, é necessária uma reflexão que desmobilize a dispersão de significados que suscitam o medo irracional dos indivíduos em relação à doença, ainda interpretada como uma condição derivada de comportamentos desviantes - e, portanto, suscetíveis de apreciações moralistas.

$\mathrm{Se}$, no documentário, a realidade de um organismo debilitado é recorrente nos longos planos-sequência que explicitam as insônias, a abulia e a pele perfurada por agulhas, a doença, no entanto, jamais é figurativizada como uma desgraça, mas dimensionada no entrecruzamento de uma perspectiva biológica e de uma perspectiva sócio-política. O poder individual de escolha (ainda 
que sob parâmetros limitados) é sublinhado quando Jó, uma amiga de Joaquim que também se submete aos medicamentos experimentais, decide interromper o tratamento. Em um dos e-mails trocados com o amigo, Jó chama a atenção para a incoerência de se violentar o corpo com um tratamento extremamente agressivo em troca de mais alguns anos de vida.

A questão do tempo, neste e noutros segmentos do filme, releva de um ponto de vista que, no agenciamento de imagens provenientes de registros heterogêneos, alcança um efeito de sentido de anacronicidade. Embora os eventos históricos remontem a uma temporalidade específica, sua representação reapresentação - em um presente enunciativo, que evidentemente se completa no exercício espectatorial, congrega as imagens visuais como "símbolos particularmente efetivos de estados psicológicos que podem ser recriados no espectador" (Rampley, 1999: 112). Esses fragmentos constituem-se como imagens sobreviventes não tanto na medida em que atestam, comprobatoriamente, a veracidade dos eventos históricos, mas sobretudo por seu valor de comoção: o poder de atualizar, ressignificando, a dimensão sensível de uma experiência pretérita: o "isso foi" em face do "agora", único tempo forte da memória.

\section{Imitação da vida: o presente como condição da memória}

A emergência das lembranças como uma operação que só se torna possível no presente é enfatizada em E agora? Lembra-me por meio da contemplação de uma das passagens das Confissões, de Santo Agostinho, em que o teólogo alude à impossibilidade de se apreender o tempo: a rigor, não podemos medilo, pois o passado já não existe; o futuro ainda não é; e o presente carece do espaço (distância) necessário a qualquer intento de mensuração. Nesse âmbito, o passado (como rememoração) e o futuro (como aquilo que se espera) são dimensões cujo valor, na mente dos homens, depende necessariamente do agora, do momento em que se vive. O conceito de tempo tem, então, como lastro as ideia de memória e de expectativa.

A reflexão agostiniana sobre o tempo nos âmbitos da cosmologia, como movimento próprio à ordem da vida, e da interioridade subjetiva, em que se enfatiza o aspecto da consciência da finitude, perpassa a estruturação do documentário de Joaquim Pinto - e o momento em que o realizador "se encontra" com as palavras do teólogo, por influência das leituras de Nuno, é revelador: se até então Joaquim pouco se interessara pelas ideias do "inventor da guerra santa e do pecado original", a relação intrínseca das Confissões com o filme, na referida tematização do tempo e da memória, emerge com força expressiva.

Outra semelhança entre as obras diz respeito à condição do $e u$ que enuncia. Santo Agostinho dirige-se a Deus, a alteridade absoluta, em seu exercício 
confessional. Mais do que a conformação de um interlocutor, o teólogo intenta colocar à prova a própria condição identitária: se Deus é aquele que tudo sabe e a tudo conhece (a quem, portanto, não se pode mentir), será, por consequência, uma espécie de "fiador" da autenticidade do ato de confissão. Em $E$ agora? Lembra-me, é também em relação às manifestações da alteridade (os semelhantes, as formas não-humanas de vida, a própria experiência da linguagem) que o $e u$ afirma sua condição de existência. Apenas em relação ao $t u$, o $e u$ tem razão de ser. É pela experiência subjetiva que a realidade pode ser compreendida e dimensionada, mas não há como se cogitar o lugar da primeira pessoa senão em uma relação com o outro.

Essa asserção se radicaliza em uma das últimas sequências do documentário, quando imagens do ciclo da vida natural, em seus movimentos e em suas paragens, são acompanhadas pela reflexão: "Vivemos tempos tristes. Pobre ideia de que podemos matar toda a vida. Quando tivermos voltado ao pó, a vida respirará aliviada". No caminho que devolverá ao pó toda forma de existência, entretanto, o homem é o único que intenta, ilusoriamente, ludibriar a própria morte. É pela experiência da linguagem que o sujeito aspira a uma distensão dos limites, forjando uma prosaica história da eternidade, aquela que sobreviverá a ele à maneira de um vestígio.

Como exercício imaginativo (no sentido de se lançar à produção de imagens de uma história até então inaudita), a trajetória de E agora? Lembra-mee, de modo mais abrangente, a da própria experiência do cinema - é a de uma imitação: aquela que se perfaz com a matéria-prima da vida, mas que, em alguma medida, desloca poeticamente os limites de sua contingência. Não é por acaso, pois, que Joaquim Pinto alude à leitura de uma biografia da atriz Lana Turner no mesmo momento em que, pela primeira vez, ouvia notícias "daquela doença que matava homossexuais na América". Após uma carreira conturbada e um período de ostracismo, Turner consegue voltar ao cinema pelas mãos de um produtor (Ross Hunter), que "lhe levava flores e, sem interferir, criava as condições para que [o filme] A imitação da vida acontecesse".

Ross Hunter de sua própria história, Joaquim Pinto não apenas cria as condições para permanecer vivo, mas também torna essa experiência prenhe de desejo. É preciso querer para crer. Os votos de "bom Natal" antecedem o último plano-sequência do filme, que começa com a imagem de um caminhão de carga que transporta perus engaiolados (derrisória analogia com o destino do homem), mas termina com uma panorâmica da estrada ao horizonte: o "lembrar-se do agora" como uma passagem, que, mesmo conduzindo ao pó, torna possível a imitação da vida com aquilo que, em nós, sobreviverá à nossa finitude. 


\section{Referências bibliográficas}

Agamben, G. (2007). Profanações. São Paulo: Boitempo.

Agamben, G. (2013). A comunidade que vem. Belo Horizonte: Autêntica.

Barthes, R. (2004). A morte do autor. O rumor da língua: 57-64. São Paulo: Martins Fontes.

Benjamin, W. (1984). Alegoria e drama barroco. Origem do drama barroco Alemão: 181-211. São Paulo: Brasiliense.

Comolli, J.-L. (2008). Ver e poder - a inocência perdida: cinema, televisão, ficção, documentário. Belo Horizonte: Editora UFMG.

Deleuze, G. \& Guattari, F. (1997). O liso e o estriado. Mil platôs - capitalismo e esquizofrenia, 5: 179-214. São Paulo: editora 34.

Deswarte, S. (1983). Les De Aetatibus Mundi Imagines de Francisco de Holanda. Monuments et mémoires de la Fondation Eugène Plot, 66(1): 67190.

Didi-Huberman, G. (2010). O que vemos, o que nos olha. São Paulo: Editora 34.

Ferreira, F. (2014). Vamos aprender a estar vivos (e talvez a ser melhor do que somos). Expresso: entrevista com Joaquim Pinto, Lisboa, 22 de setembro. Disponível em http://expresso.sapo.pt/cultura/vamos-aprendera-estar-vivos-e-talvez-a-ser-melhor-do-que-somos=f887951

Gester, J. (2014). Sur la planète thérapie. Libération, Paris, 18 de novembro. Disponível em http://next.liberation.fr/cinema/2014/11/18/sur-la-planetetherapie_1145532

Rampley, M. (1999). Archives of memory: Walter Benjamin's Arcades Project and Aby Warburg's Menmosyne Atlas. In A. Coles (Ed.), The optic of Walter Benjamin, vol. 3 (pp. 94-117). London: Black Dog.

Ricoeur, P. (2003). Memória, história, esquecimento. Palestra realizada na Conferência Internacional Hauting Memories? History in Europe after authoritarianism, Budapeste: Publicações Universidade de Coimbra. Disponível em http://www.uc.pt/fluc/lif/publicacoes/textos_disponiveis_ online/pdf/memoria_historia

Safatle, V. (s.d.). O que vem após a imagem de si?. Revista Trópico, s.p. Disponível em http://www.revistatropico.com.br/tropico/html/print/2793. htm

Santo Agostinho (1996). Confissões. Coleção Os Pensadores. São Paulo: Nova Cultural. 
Sibilia, P. (2013). A construção de si como um personagem real: autenticidade intimista e declínio da ficção na cultura contemporânea. Eco Pós - Revista do Programa de Pós-Graduação da Escola de Comunicação da UFRJ, Dossiê: Imaginando o real: novos realismos, Rio de Janeiro: UFRJ, 15(3): 22-46.

Sontag, S. (1989). Aids e suas metáforas. São Paulo: Companhia das Letras.

\section{Filmografia}

E agora? Lembra-me (2013), de Joaquim Pinto. 